\section{Sulfur Cycle}

Martin A. Schoonen

Brookhaven National Laboratory, Upton, NY, USA

Department of Geosciences, Stony Brook University, Stony

Brook, NY, USA

\section{Definition}

The global sulfur cycle refers to the transfer of sulfur between the upper lithosphere, hydrosphere, pedosphere, biosphere, and atmosphere as a result of geological, biological, and anthropogenic processes. Sulfur passing through the cycle is subject to redox reactions with oxygen, carbon, and iron as major reactants, which lead to a tight coupling of the global cycles for these elements.

\section{The Major Sulfur Reservoirs on Earth}

Most sulfur on Earth involved in the global sulfur cycle is retained in the upper lithosphere and marine sediments (Table 1). A large unknown amount of sulfur residing in the Earth's core and mantle is effectively sequestered and excluded from the global sulfur cycle. The oceans contain most of the sulfur residing in the hydrosphere, dwarfing the amount of sulfur in lakes and rivers (Table 1). The amount of sulfur contained in soils and biomass is roughly four orders of magnitude smaller than the amount of sulfur in the oceans, while the atmosphere represents the smallest reservoir of sulfur on Earth (Table 1). Table 1 not only summarizes estimates of the amount of sulfur contained in the major reservoirs; it also indicates the most abundant forms of sulfur in each reservoir.

\section{The Modern Natural Global Sulfur Cycle}

The modern natural global sulfur cycle is dominated by processes involving transfer of sulfur in and out of the oceans (Sievert et al., 2007). A significant amount of sulfur is lofted into the air in the form of small sulfate-containing salt crystals; see Figure 1. Most of the particles settle rapidly back into the ocean, but some are transported over land and are removed from the air mass through precipitation or by settlings as dry deposition. Removal of sulfate through microbial reduction in marine sediments to sulfide, followed by the formation of pyrite, is a major process that removes sulfate from the ocean (Schoonen, 2004). Some sulfate is also removed from the oceans in the form of evaporate minerals and as a trace constituent of sedimentary carbonates (Staudt and Schoonen, 1995). Microbial conversion of sulfate into volatile organo-sulfur compounds in marine environments also contributes to a transfer of sulfur from the ocean reservoir through the biosphere into the atmosphere (Sievert et al., 2007).

Inputs to the ocean reservoir in the natural sulfur cycle are dominated by weathering of sulfate-containing evaporative deposits and weathering of pyrite-containing sediments. Removal of volcanogenic sulfur emissions via precipitation or dry deposition into the oceans constitutes a small input, although the magnitude of this flux varies with volcanic activity (Jones et al., 2016).

The magnitudes of all the fluxes in the modern natural global sulfur cycle are difficult to reconstruct because contributions from human activity are difficult to separate from natural contributions. New approaches relying on the study of multiple $\mathrm{S}$ isotope systematics are promising (Tostevin et al., 2014), but it remains difficult to close the natural sulfur budget. 
Sulfur Cycle, Table 1 Major sulfur reservoirs on Earth ${ }^{\mathrm{a}}$

\begin{tabular}{l|l|l}
\hline Reservoir & Major forms of sulfur & Mass (Tg S) \\
\hline Atmosphere & $\begin{array}{l}\text { Gas: } \mathrm{H}_{2} \mathrm{~S}, \mathrm{SO}_{2}, \mathrm{DMS}, \mathrm{OCS} \\
\text { Aerosols: } \mathrm{H}_{2} \mathrm{SO}_{4},\left(\mathrm{NH}_{4}\right)_{2} \mathrm{SO}_{4}\end{array}$ & 4.8 \\
\hline Pedosphere and biosphere & Sulfates, organic S, pyrite & $3 \times 10^{5}$ \\
\hline Rivers and lakes & $\mathrm{SO}_{4}{ }^{2-}$ & 300 \\
\hline Oceans & $\mathrm{SO}_{4}{ }^{2-}$ & $1.3 \times 10^{9}$ \\
\hline Marine sediments & Pyrite, gypsum, anhydrite & $3 \times 10^{8}$ \\
\hline Lithosphere & Gypsum, anhydrite, metal sulfides, sulfur & $2 \times 10^{10}$ \\
\hline
\end{tabular}

${ }^{a}$ Based on Brimblecombe (2014) and Jones et al., (2016)

${ }^{\mathrm{b}} \mathrm{Tg}$ is $10^{12} \mathrm{~g}$

Sulfur Cycle,

Figure 1 Simplified modern natural sulfur cycle. The weight of the arrow indicates the relative importance of a given flux. There is considerable cycling of sulfur that involves uptake and release of sulfur within the overlaps of hydrosphere, lithosphere, and biosphere as indicated by the curved arrows. Anthropogenic activities have a significant effect on the natural sulfur cycle; see Figure 2, which makes it difficult to determine the absolute magnitude of the modern natural fluxes.

${ }^{\text {\#}}$ CAS carbonate associated sulfur.

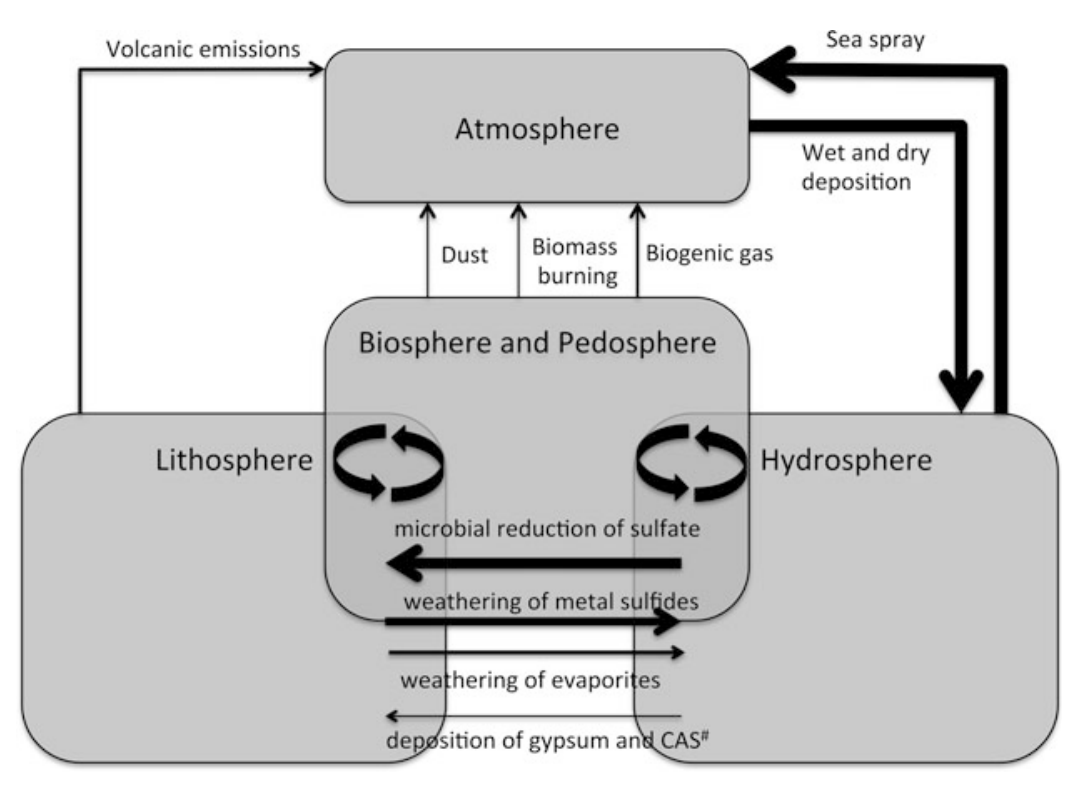

\section{Sulfur Cycle Through the Earth's History}

As the Earth evolved, so did the sulfur cycle (Rickard, 2012; Brimblecombe, 2014). Microbial processes play a significant role in the modern natural sulfur cycle (Figure 1). Hence, on a prebiotic Earth, the sulfur cycle would have been dominated by emissions of volcanic sulfur gases - predominantly $\mathrm{SO}_{2}$, with minor $\mathrm{H}_{2} \mathrm{~S}$ - into the atmosphere and removal of sulfur from the atmosphere through photochemical reactions. There was likely very little subaerial crust, all but eliminating gypsum deposition and dissolution as major processes at this early time. Dissolved reduced iron (Fe(II)), leached from crustal rock interacting with ocean waters, would have limited the amount of hydrogen sulfide in solution through iron sulfide precipitation. A higher heat flow on the early Earth would have promoted widespread hydrothermal circulation of ocean water through the crust. The net effect would have been sequestration of sulfate as metal sulfide as ocean water interacted with the crust at elevated temperatures.

The emergence of life triggered significant changes in the sulfur cycle (Rickard, 2012). The most profound change to the sulfur cycle occurred at the time of the transition from an anoxic atmosphere to an oxic atmosphere around $2.3 \mathrm{Ga}$ as a result of the emergence of photosynthetic bacteria producing oxygen as a waste product. Detailed studies exploiting multiS-isotope systematics point to a sulfur cycle that is largely dominated by inorganic processes up to this point in the Earth's history (Johnston, 2011). Once the atmosphere contained molecular oxygen, volcanogenic sulfur emitted into the atmosphere was readily oxidized to sulfate. Besides the accumulation of oxygen in the atmosphere, the growth of continents enabled chemical weathering of sulfide-containing rocks through oxidation, resulting in the enhanced transport of sulfate to the ocean. This sets the stage for sulfate-reducing bacteria - possibly long present in the ocean but limited by the 


\section{Sulfur Cycle,}

Figure 2 Annual fluxes of sulfur ( $\mathrm{Tg} / \mathrm{a})$. Fluxes based on Brimblecombe (2014) and Berner and Berner (1996) The flux associated with wildfires is estimated to be a factor of ten smaller than biomass burning associated with crop waste burning and land-clearing activities.

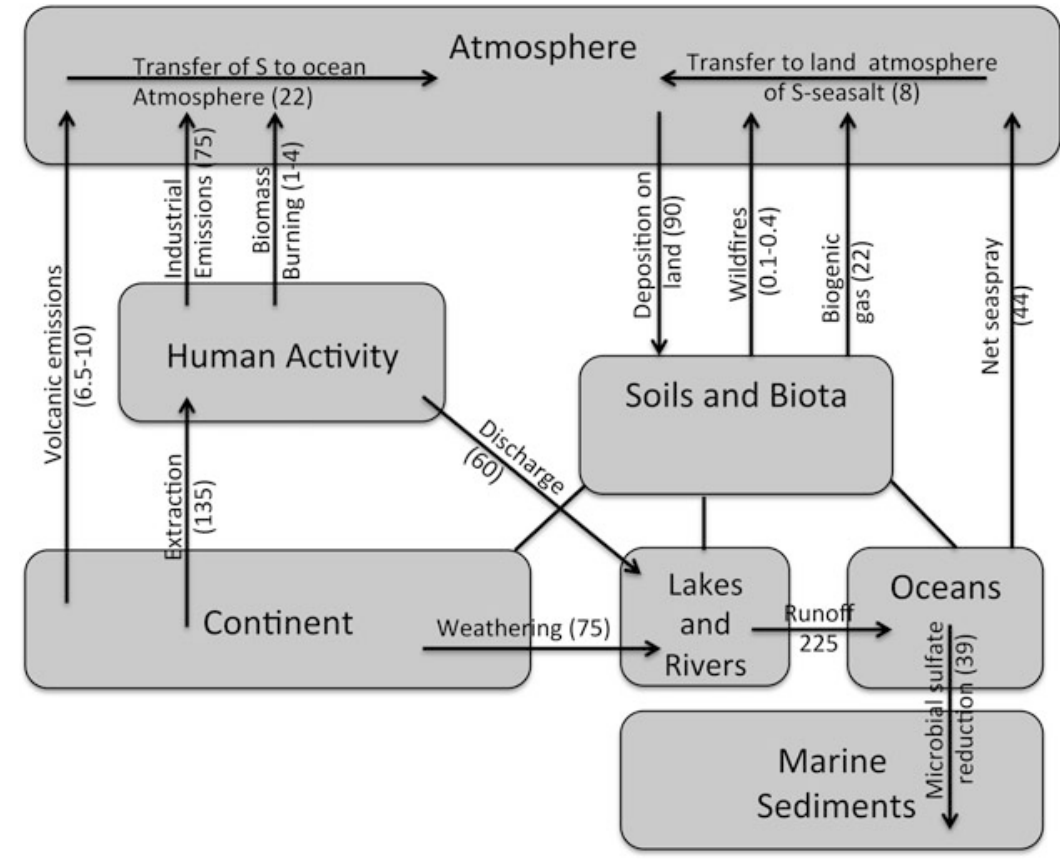

the sea. Roasting of metal sulfide ores, a necessary step to provide society with metals such as zinc and copper, releases a significant amount of $\mathrm{SO}_{2}$. International shipping, which relies on burning of S-rich bunker fuel, amounts to about $10 \%$ of the global anthropogenic $\mathrm{SO}_{2}$ emissions (Klimont et al., 2013).

The magnitude of the anthropogenic perturbation of the sulfur cycle is illustrated in Figure 2. For example, it is estimated that more than half of the sulfur transported to the oceans by rivers and $75 \%$ of the sulfur emissions to the atmosphere are anthropogenic in origin (Berner and Berner, 1996).

On a global scale, the emissions of $\mathrm{SO}_{2}$ have dropped recently (Klimont et al., 2013). Changes in economic activity have a profound effect on the demand for fossil fuel, metals, and transportation of goods via international shipping, and the recent (2005-2011) drop likely reflects the impact of a global recession. However, it is projected that economic growth in India, an expansion of international shipping, and growth of emerging economies in Africa will add to the atmospheric $\mathrm{SO}_{2}$ burden. At the same time, stricter environmental regulations are expected to lead to a broader application of technologies to scrub $\mathrm{SO}_{2}$ from flue gas in China, Europe, and North America. While this will lead to a long-term, sustained decrease in $\mathrm{SO}_{2}$ emissions, it only addresses one of the anthropogenic processes that contributes to the imbalance of the global sulfur cycle (Klimont et al., 2013; Brimblecombe, 2014). or metal sulfides creates sulfur-containing dust as well as sulfide-containing mine waste that often reacts with water and air to form acid mine drainage. Oxidation of mine waste contributes significantly to the riverine flux of sulfate out to 


\section{Conclusions}

The modern global sulfur cycle is out of balance as a result of anthropogenic activity. The sulfur cycle has changed as the Earth evolved. On the prebiotic Earth, volcanic emissions played a key role in the sulfur cycle. This cycle may have remained largely unchanged, until free oxygen accumulated in the atmosphere as photosynthetic microbes emerged. The presence of oxygen and the growth of continents fundamentally changed the sulfur cycle, with evaporate deposition, oxidative weathering of pyrite-containing rocks, and dissolution of evaporites becoming important processes. One of the outcomes was a built up of sulfate in the oceans that allowed microbial sulfate reduction to emerge as an important process. It is thought that the flux of sulfate removal from the ocean through microbial sulfate reduction has grown with the increased atmospheric sulfur deposited in the ocean as a result of human activity. Adoption of new mitigation technologies is likely to reduce the anthropogenic emissions of sulfur.

\section{References}

Berner, E. K., and Berner, R. A., 1996. Global Environment. Upper Saddle River: Prentice-Hall.
Brimblecombe, P., 2014. 10.14 - The global sulfur cycle A2. In Holland, H. D., and Turekian, K. K. (eds.), Treatise on Geochemistry, 2nd edn. Oxford: Elsevier, pp. 559-591.

Johnston, D. T., 2011. Multiple sulfur isotopes and the evolution of Earth's surface sulfur cycle. Earth-Science Reviews, 106, 161-183.

Jones, M. T., Jerram, D. A., Svensen, H. H., and Grove, C., 2016. The effects of large igneous provinces on the global carbon and sulphur cycles. Palaeogeography Palaeoclimatology Palaeoecology, 441, 4-21.

Klimont, Z., Smith, S. J., and Cofala, J., 2013. The last decade of global anthropogenic sulfur dioxide. Environmental Research Letters, 8.

Rickard, D., 2012. The Evolution of the Sedimentary Sulfur Cycle, Sulfidic Sediments and Sedimentary Rocks. Amsterdam: Elsevier, pp. 685-766.

Schoonen, M. A. A., 2004. Mechanisms of sedimentary pyrite formation. In Amend, J. P., Edwards, K. J., and Lyons, T. W. (eds.), Sulfur Biogeochemistry - Past and Present. Boulder, Geological Society of America. pp. 117-134.

Sievert, S. M., Kiene, R. P., and Schulz-Vogt, H. N., 2007. The sulfur cycle. Oceanography, 20, 117-123.

Staudt, W. J., and Schoonen, M. A. A., 1995. Sulfate incorporation into sedimentary carbonates. In Vairavamurthy, M. A., and Schoonen, M. A. A. (eds.), Geochemical Transformations of Sedimentary Sulfur. Am. Chemical Society, Washington DC. pp. 332-345.

Tostevin, R., Turchyn, A. V., Farquhar, J., Johnston, D. T., Eldridge, D. L., Bishop, J. K. B., and McIlvin, M., 2014. Multiple sulfur isotope constraints on the modern sulfur cycle. Earth and Planetary Science Letters, 396, 14-21. 